(1)

\author{
Research
}

\title{
A Case-Based Model for Assessing the Effectiveness of Information Systems Outsourcing
}

\section{Erkan Uçar \& Semih Bilgen}

To cite this article: Erkan Uçar \& Semih Bilgen (2013) A Case-Based Model for Assessing the Effectiveness of Information Systems Outsourcing, Journal of Information Technology Case and Application Research, 15:3, 27-60, DOI: 10.1080/15228053.2013.10845721

To link to this article: https://doi.org/10.1080/15228053.2013.10845721

\section{曲 Published online: 07 Jul 2014.}

Submit your article to this journal

ЦIll Article views: 97

4 Citing articles: 2 View citing articles 


\title{
A CASE-BASED MODEL FOR ASSESSING THE EFFECTIVENESS OF INFORMATION SYSTEMS OUTSOURCING
}

\author{
Erkan Uçar \\ Computer Technology and Information Systems Department \\ Bilkent University, Ankara, Turkey \\ Semih Bilgen \\ Electrical and Electronics Engineering Department \\ Middle East Technical University, Ankara, Turkey
}

\begin{abstract}
The objective of the research reported in this paper is to construct a model for assessing the effectiveness of Information Systems (IS) outsourcing. "Lack of in-house expertise" and "cost effectiveness" are widely accepted as major factors of motivation for IS outsourcing. In contrast with the decision models which are executed before an outsourcing engagement (a-priori), this effectiveness assessment model will be an a-posteriori guide which will enable clients to assess their outsourcing performance and re-evaluate their business and management strategies. Although various decision models and analytical frameworks have been proposed before, the literature is not abundant on a complete qualitative model. This paper examines the factors for outsourcing effectiveness through qualitative research conducted with multiple case studies for information systems developed for public organizations in the specific context of Turkey. A conceptual model consisting of various hypotheses is constructed and qualitatively evaluated.
\end{abstract}

Keywords: Information systems, outsourcing, qualitative research, case study, effectiveness, Turkey.

\section{INTRODUCTION}

Outsourcing can be defined as transferring internal business activities to an external provider. It is not a new concept since traditional subcontracting can be viewed as the origin of today's outsourcing. In its simplest view, it is based on a make/buy decision and today, it constitutes a highly strategic management concept. Similarly, information systems (IS) outsourcing is the transfer of part or all of the IS functions to an external vendor (Grover, Cheon, and Teng, 1996). Among the common IS outsourcing categories, we can mention information technology (IT) infrastructure outsourcing, application development outsourcing, and integration outsourcing. In short, it implies that clients - usually being non-IT entities - use vendors to manage their own IS. Since information systems not only include IT but also make use of human resources and business processes, vendors should be capable of working on both IT and non-IT domains. Being a major parameter of information management of a company, IS outsourcing should be aligned with IT planning. 
Throughout the last two decades, IS outsourcing has been studied from various perspectives. The seminal paper by Lacity and Hirschheim (1993) being among the first to elaborate on fundamental issues, on the one hand, IS have been considered as commodity services, whereas on the other, "outsourcing IS" is viewed at a more strategic level than other organizational functions. Consequently, the industry is developing, the number of providers and the range of outsourced functions are growing, and eventually the rights and wrongs of the whole process are becoming more critical. Today, IT management (together with CIOs and executive management) is challenged by the cost and risk of IT investments which can be quite critical for the firm. Moreover, the speed and dynamics of technological developments in this domain require skilled and experienced IT staff to cope with this dynamism (Loh and Venkatraman, 1992). Therefore, the number of firms that consider outsourcing part or all of IS functions is increasing every day. On the other hand, Hu, Saunders and Gebelt's research (1997) which analyzed data from 175 companies showed that the influences of media, vendor pressure, and internal communications between the managers of firms were the main triggers for clients to adopt IS outsourcing (rather than the famous Kodak effect). Palvia (1995) has studied the pros and cons from a dialectic viewpoint. A more recent and comprehensive literature review on IS outsourcing together with future research directions has been published by Lacity, Khan, and Willcocks (2009). In another study, Sashikala (2010) presents a theoretical framework for outsourcing actions as a guideline for companies on why and how to outsource.

In the present study, the problem of IS outsourcing effectiveness is empirically investigated. By "effectiveness" we mean the degree to which outsourcing reasons/motives of clients are achieved and the level to which in-house problems of concern are solved (Figure 1). The first case presented in this paper serves an exploratory purpose and is followed by two validatory cases. To construct the theoretical basis of the study, firstly, determinants of a typical IS outsourcing life cycle will be presented based on a brief review of the literature. Secondly, conceptual foundations of IS outsourcing derived from the fields of economics, management, and sociology will be highlighted. Finally, traditional and contemporary approaches to developing the software that underlies the IS will be considered as factors that influence outsourcing effectiveness. After elaborating on these three viewpoints, our research methodology will be explained and then, the case studies carried out with various vendors and public sector clients in Turkey will be described, leading to the assessment model that consists of hypotheses derived from the analyses of these cases. Each hypothesis will be formulated and incorporated into the conceptual model of effectiveness after discussing the pertinent issues in the context of the cases. We will conclude with a summary, a number of remarks and suggestions for future research directions. 


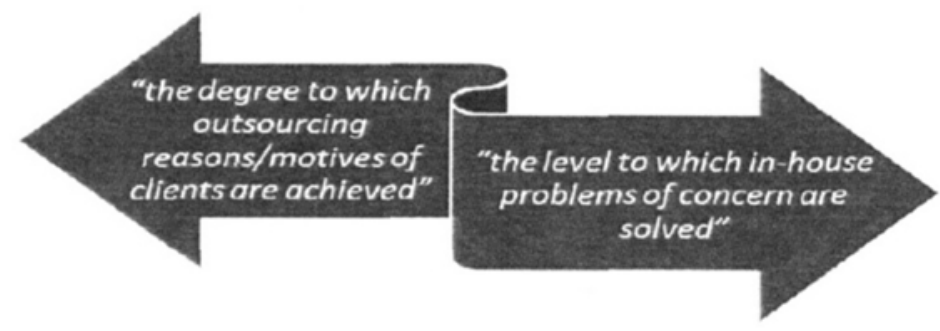

Figure 1. What we mean by IS outsourcing effectiveness.

\section{DETERMINANTS OF THE IS OUTSOURCING LIFE CYCLE}

\section{Strategic Intent}

For IS outsourcing, clients need to form their strategic intent in terms of desired outcomes. One of the most suitable classifications of strategic intents for outsourcing is presented by DiRomualdo and Gurbaxani (1998). According to this study, there are three main classes: IS improvement, business impact, and commercial exploitation. The main concentrations of the popular IS improving outsourcing deals are to cut costs and to increase the IS effectiveness. In such cases, clients expect better performance from the IS resources at hand. Achieving business impact is another reason for outsourcing. A new IS can improve the client's business processes. Finally, commercial exploitation can be achieved through a strong partnership with the vendor in order to create new profits from IS resources. One way of performing this is to license previously internal IS products and services to be marketable to other organizations. Innovation is the key factor here.

More recently, Beasley, Bradford, and Dehning (2009) have analyzed how strategic intent of outsourcing forms a value impact on clients. This empirical study has shown that there is a significant relation between the strategic intent and the firm size. One reason for this relation is the behavior of the shareholders of large firms where they believe that economies of scale are already established so outsourcing IS should have reasons other than cost reduction.

One of the important frameworks modeled to assist decision making as to which IS functions to outsource was designed in 1995 by Cronk and Sharp. The motivation behind this research was two conflicting arguments, namely, whether the strategic role of IS allows or prevents outsourcing. The core of this framework was the well-known core competency theory and segmentation of the IT functions accordingly.

Recent research by Dibbern, Chin and Heinzl (2012) showed how strategic IS outsourcing decisions were influenced by systemic factors (influences that occur when various IS functions work together effectively) and how dependent these are on cultural contexts. The research was performed with surveys on two different cultures; Germany, considered "moderately individualist," and United States, considered "strongly individualist". 
Another strategic intent of outsourcing is to enable knowledge transfer from vendors to clients. Al-Salti and Hackney's research on studying the factors which effect the knowledge transfer in IS outsourcing in the public sector suggests that different types of factors exist: knowledge-related, client-related, vendor-related and relationship-related (Al-Salti \& Hackney, 2011). This exploratory research was carried out with eight largest public sector organizations of Oman and supports the importance of having an organizational culture supporting innovation, learning and cross-boundary knowledge transfer.

The underlying theories of outsourcing, when mapped to business strategies, affect the differentiation between the clients who apply outsourcing for IS and the ones who do not (Aubert, Beaurivage, Croteau, \& Rivard, 2008; Jurison, 1995). On the other hand, degree of outsourcing that we study in the next section has a direct influence on the type of strategic intent.

\section{Degree of Outsourcing}

Degree of outsourcing is defined as the scope of outsourcing in terms of the client's IS budget. Usually, an outsourcing deal which corresponds to $80 \%$ or more of the client's budget is called total outsourcing. If this figure is in the range of $15 \%-25 \%$, then it is called selective outsourcing (Willcocks \& Lacity, 1999). Decisions about this degree are quite critical since there is a high correlation between the scope and the risks/rewards of the project.

Naturally, total outsourcing deals contain more risks and more rewards than selective outsourcing deals which in return have a direct effect on the success or failure of the project. Barthelemy and Geyer (2004) have pointed out that most clients favor selective outsourcing in cases where the client has a strong IT department or is in the IS market. On the other hand, when the main motivation is to minimize IT costs, clients prefer total outsourcing.

Gulla and Gupta have suggested a framework for clients to undertake the right IS outsourcing decision and the degree of outsourcing (Gulla \& Gupta, 2012). According to this framework, the outsourcing degree is effected by a lot of outsourcing drivers and the managers should carefully analyze these drivers in short, medium as well as in long term on the IS performance. Moreover, they should align each one of them with the organization's business goals. The framework uses analytical hierarchy process for optimizing the decision on the degree of the outsourcing deal and is applied to three Indian banks.

There are three major lessons learned related to the degree of outsourcing: (i) whether total or selective, outsourcing degree should be identified well since it has direct consequences throughout the outsourcing deal. (ii) The degree should be confirmed after a careful examination of the strategic intent for the deal in order to be consistent with the project goals. (iii) Upon the analysis of the outsourcing degree, there may still be an option to go back and build the system in-house.

\section{Vendor Selection}

Identifying the potential role and contribution of vendors is critical in the outsourcing process. High expectations of clients end up in strong and sometime over-structured contract items. Such 
an approach affects the outsourcing relationship directly. The determinants of this relationship can be considered in two categories: contextual relationship including mutual benefits, commitment, and predisposition, and active relationship including shared actions, distinctive competencies, and organizational linkage (Pinnington \& Woolcock, 1997).

In the vendor selection process, clients should follow past experiences with similar purchases where they achieved success. Moreover, identification of potential vendors to meet the client's requirements should be the first step to take. Then, a study on which vendors have the sufficient skill-sets for the deal has to be performed. The concentration should be on understanding the infrastructure, values, and methodologies (Feeny, Lacity, \& Willcocks, 2005). According to Feeny et al., the vendor capabilities that should be evaluated can be listed as domain expertise, business management, behavior management, sourcing skills, technology exploitation, process reengineering skills, customer development skills, planning and contracting skills, organization design, governance skills, project management skills, and leadership skills.

A decisive factor in the vendor selection process is benchmarking the vendor costs against the cost that would accrue if the system is built in-house. Secondly, the client must apply a duediligence process, to estimate and test whether the vendor has sufficient resources and skills to complete the project. The due-diligence process usually consists of an information exchange beyond the scope of the RFP. Kern, Willcocks, and van Heck (2002) state that "selecting a supplier is a costly undertaking in terms of time, effort, and resources. However, the investment in identifying the right supplier and contract bid is paramount to the success of the overall outsourcing venture".

Kim and Chung (2003) have studied 207 outsourcing cases and they claim that one of the most critical factors for successful IS outsourcing is the set of vendor capabilities since most of the clients prefer outsourcing when they do not have the sufficient expertise internally. Expectation of a successful outcome increases when the vendor has the experience and financial resources to match the client's goals.

\section{Contract and Relationship Management}

Operating the contract clauses is not sufficient for success, since management of vendor relationship is just as important as contract management. These two concepts should be worked together for a beneficial outsourcing deal. Focusing too much on the contract may achieve a successful IS in the end. But is it sufficient for a healthy outsourcing life cycle - especially for the future deals with the same vendor?

Numerous studies have addressed the issue of client-vendor partnership and the management of this relationship (Espino-Rodriguez \& Rodriguez-Diaz, 2008; Heckman, 1999; Heiskanen, Newman, \& Eklin, 2008; Kern \& Blois, 2002; Kishore, Rao, Nam, Rajagopalan, \& Chaudhury, 2003; Krishnamurthy, Jegen, \& Brownell, 2009; Lee, 2001; Lee \& Kim, 1999; Shi, Kunnathur, \& Ragu-Nathan, 2005; Tan \& Sia, 2006). 
Official conduct of IS outsourcing definitely requires a strong and structured contract. On the other hand, a productive relationship will enable an added value for the whole deal (Satther \& Gottschalk, 2008). Bryson and Ngwenyama (2000) proposed a contract structuring approach for mutual benefits on clients and vendors. Their research was based on constructing incentive schemes for improving vendor performance differentiating between deals having single and multiple vendors. Upon the fact that information processing costs can be fixed or variable, types and structures of outsourcing contracts can vary as well.

The cost of developing a strong relationship between the client and the vendor is usually high. On the other hand, once the costs are neglected and moreover a "partnership" between the parties is established, the probability of a successful outcome increases. Of course, such efforts are results of managerial decisions and highly strategic in the contracting world. Examples of such efforts are described by Klepper (1995). Moreover, the relationship established may vary depending on clients working with single or multiple vendors. Lee, Heng, and Lee (2009) have studied multivendor outsourcing relationship management from three dimensions, namely; structural, affective, and cognitive.

The issue of trust merits special focus in outsourcing relationships. Sabherwal (1999) defines trust as "A state involving confident positive expectations about another's motives with respect to oneself in situations entailing risk". A high level of trust is needed in an outsourcing relationship since it can be viewed as a strategic partnership. Trust between the client and the vendor should start at the very beginning of the relationship (Goo \& Huang, 2008). The contract should be prepared without favoring any one of the parties. On the other hand too much or too little trust can harm the success of the IS at stake. Some of the other critical factors of trust are vendor's previous clients (references), performance level, investments made for the outsourcing deal, commitment, consistency, and obeying the security/confidentiality restrictions (Oza, Hall, Rainer, \& Grey, 2006).

Moon et al. created and applied a relationship-based framework to 178 public outsourcing projects in Korea (Moon, Swar, Choe, Chung \& Jung, 2010). Results of this research indicate that projects with low strategic impact require a support type of relationship where contract sizes are small and the deals show a low success rate. Moreover, public sector outsourcing requires management of a long-term relationship since it is more complex and strategic.

\section{CONCEPTUAL FOUNDATIONS}

There are a number of relevant theories of different disciplines that have inspired IS outsourcing researchers so far, viz. transaction cost economics and agency theory from economics, game theory, resource dependency theory, resource based view, and core competency theory from management strategy, institutional theory, social exchange theory, innovation diffusion theory, and power-political theory from sociology. With the booming popularity of IS outsourcing since $90 \mathrm{~s}$, quite a number of academic studies on these theoretical models have been carried out in order to perceive the relation between the decision making and/or implementation of outsourcing and how clients perform their business strategies, how information systems are governed in their 
transactions, and how social and organizational norms effect these processes (Willcocks \& Lacity, 1995). We have selected transaction cost economics, agency theory, resource dependency theory, and resource based view, as the four most commonly used theoretical models, in the light of Cheon, Grover, and Teng's (1995) study in order to understand clients' outsourcing strategies and formulate our research questions.

The main idea behind Transaction Cost Economics (TCE) is determining the make-or-buy selection. An asset is called firm-specific when its value for different uses is quite lower than its value for its current use. Existence of such assets allows opportunistic vendors to cause significant losses for the client (Nam, Rajagopalan, Rao, \& Chaudhury, 1996). In TCE, this factor is called asset specificity. Often, it is cheaper to buy systems with low asset specificity even if clients are capable of developing them. On the other hand, processes like IS planning and control can be highly client-specific, i.e. with high asset specificity, therefore hard to obtain from the market. Large clients with strong IS departments may not favor outsourcing. Moreover, clients and vendors can go into an outsourcing deal once or multiple times. Renegotiation and consequent renewal of outsourcing contracts is quite common. Aubert, Rivard, and Patry's (2004) empirical research on 335 firms showed that uncertainty - another important parameter of TCE plays a big role in outsourcing decisions. Clients prefer outsourcing those IS functions having low uncertainty. A very recent study by Aubert et al. proposes and tests a model of outsourcing decisions which includes antecedents of both transaction costs and production costs (Aubert, Houde, Patry, \& Rivard, 2012). Findings of the study include the differences between how IS activities should be treated in firms in knowledge intensive sectors compared to firms in less knowledge intensive sectors. Moreover, activities are not totally independent therefore management of these activities is highly correlated to coordination of them.

From an economics perspective, Agency Theory focuses on the difficulties of the information asymmetry between the principal and the contracted agents (Dibbern, Goles, Hirschheim, \& Jayatilaka, 2004). The principal represents the client and the agents represent the vendors. Asymmetric information between the parties causes uncertainty and different views of future risks. Main focus of the theory is on the conflicting goals and requirements of the parties and the cost that the client shoulders for monitoring the vendor. Therefore, the main idea should be determining the most efficient and effective contract which settles down the appropriate relationship in the deal. Moreover, Kim, Shin, and Lee studied the effects of knowledge complementarities which are defined as "the knowledge stocks of partners that collectively generate greater rents than the sum of those obtained from the individual knowledge stock of each partner" (Kim, Shin \& Lee, 2010). This can be viewed as a good example of handling the information asymmetry between the partners.

Resource Dependency Theory (RDT) was originally formalized to discuss the relationships between organizations. From the competitiveness point of view, RDT proposes that companies exchange resources to reduce uncertainty (Oh, Gallivan, \& Kim, 2006). IS outsourcing is a very typical example of the application of RDT between clients and vendors. The level of the resource dependency is formulated in terms of the resource value, number of candidate vendors supplying these resources, and the switching cost between vendors in case of failure. The degree of this 
dependency can be seized through the contract clauses. A higher number of contract clauses means the client is more dependent on the vendor. If the firm acquires these resources, the dependency level decreases.

Resource Based View (RBV) of a firm states that organizations have a lot of resources and some of these resources are more "valuable" or as Meso and Smith (2000) calls "strategic" and hence brings competitive advantage to the organization. The sustainability of such resources for a long time makes the organization more powerful in the market. RBV reflects the strategy of how a firm diversifies its products through exploiting its resources by contracting with others, instead of expanding its size, viz. via outsourcing. Outsourcing helps a lot in the sense that the firm thus focuses more on the core competencies while utilizing its resources to be used in contracted applications. Moreover, in their research on strategic sourcing with resource based perspectives, Dobrzykowski, Tran \& Tarafdar (2010) suggests that the core competencies of a firm should better be developed in-house rather than being outsourced. A detailed study of the resource based determinants in the outsourcing decision process can be found in the research of Alvarez-Suescun (2007).

\section{IS DEVELOPMENT APPROACHES}

Information systems, whether built in-house or outsourced, are highly influenced by software development methods which have evolved quite fast in the last decades. The fast growth of software development methods has also affected the way businesses made strategic decisions like outsourcing their information systems. In this section we elaborate on these concepts, mainly concentrating on outsourcing deals driven by strategies related to software development.

Firstly, process improvement models in software and systems development may increase the complexity of outsourcing deals. Among many process improvement models, Capability Maturity Model Integration (CMMI), stands as a primer in terms of its detailed context and widespread use. This framework on managing, measuring, and monitoring software development processes is also used to benchmark software vendors against others to achieve lower cost and higher quality results. With the enormous growth of the outsourcing market, a client, more than ever, needs powerful tools to measure operational performance of the vendor. Process improvement models help organizations to raise the level of quality and estimate the time and resources to develop software systems (Hyde \& Wilson, 2004).

Another, not necessarily alternative approach is agile software development. The main philosophy of the agile approach is that it initially accepts user requirements changeability and incorporates change into the product whenever necessary by incremental and iterative processes. This way, a potential product release is always ready. Communication is an important barrier in any outsourcing deal. Communication problems cause development teams to misunderstand client requirements (Hazzan \& Dubinsky, 2008). If a system is outsourced to vendors with agile know-how, by nature, more effective communication channels are established which in return saves time in documentation (brief and frequent requirements documents), forming a stronger client-vendor relationship, and increasing measurement success through regular delivery of 
working parts of the system. Trust, as considered earlier, is a common success factor both in outsourcing and in agile values. Enhancing mutual trust leads to more motivated vendor, and in return development staff.

The economics of outsourcing deals has become significant as fast and cheap vendors come up with great competitive edge. From this viewpoint, vendors who concentrate on software reuse are making their internal development processes more advantageous. Software reuse can be defined as developing software systems using existing software components. These components may be any software product from requirements to source code, from proposals to design specifications (Mili, Mili, \& Mili, 1995). Software reuse aims decreasing cost and time while increasing quality. Logically, cost of an initial investment for the process is usually high but the expected pay-off during the whole development process overcomes this cost easily. Increase in the number of reuses decreases the cost of the end product. In parallel with this argument, the richer this component library, the cheaper the software due to the logical fact that the amount of development time is minimized. Other benefits of reusing software components can be summarized as producing more standardized software, minimizing the development team, and increase the circulation of development staff between different projects (McClure, 1995). With the developments in reuse approach, organizational views that affect the process have evolved and a new concept called a Software Product Line (SPL) has emerged during late $90 \mathrm{~s}$. Clements \& Northrop (2002) define a SPL as "a set of software-intensive systems sharing a common, managed set of features that satisfy the specific needs of a particular market segment or mission and that are developed from a common set of core assets in a prescribed way". Although product line is a very old concept in manufacturing, SPL is a relatively new software development paradigm with its inter-product commonality method. These commonalities bring the advantage of economies of production. Outsourcing clients experience the benefit of acquiring information systems as a product line consisting of software systems with commonalities in terms of minimized costs, fast delivery time, and simplified trainings. Evolution of SPLs, major benefits and important case studies can be studied in Linden, Scmid, and Rommes' (2007) book called "Software Product Lines in Action".

We have studied the parameters of a typical IS outsourcing process from three perspectives from the literature: (i) determinants of an outsourcing life cycle, (ii) theoretical foundations, and (iii) effects of IS development approaches. Full definitions of these parameters that form the basis of our research methodology and the case studies we performed can be found in Appendix A. Figure 2 presents a visual summary of the framework thus established, incorporating the viewpoints derived from theoretical models of economics, management and sociology; factors that depend on the outsourcing life cycle, and possible approaches that may be applied in developing the software that underlies the IS. 
Model for Assessing the Effectiveness of IS Outsourcing

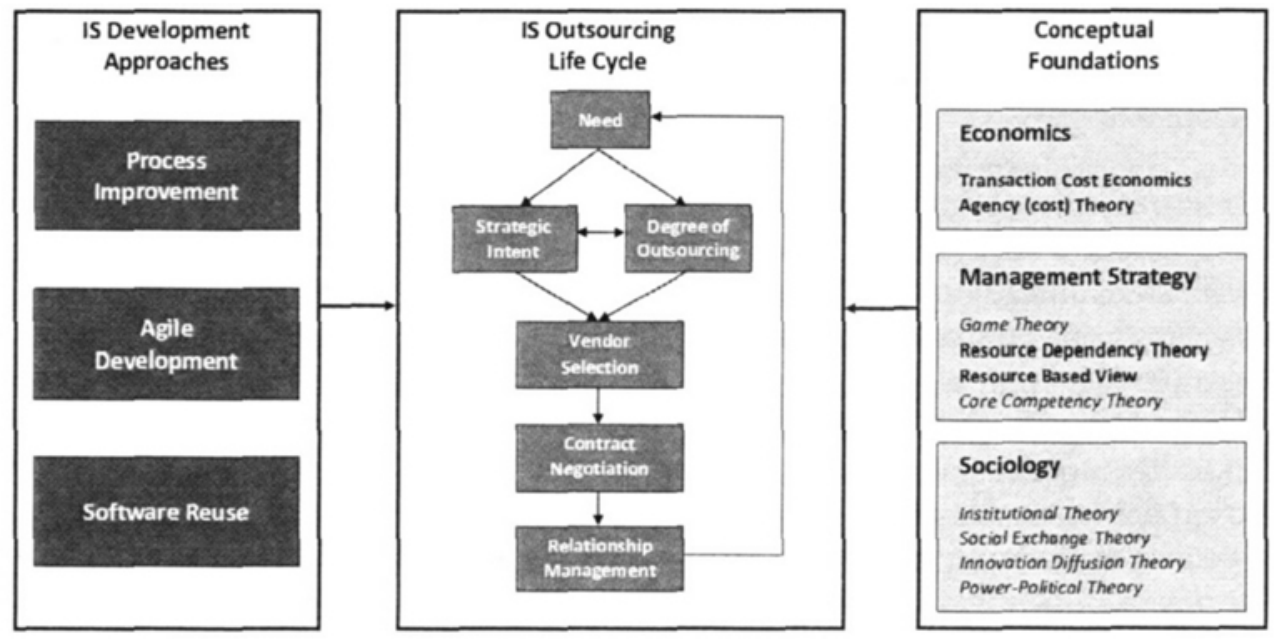

Figure 2. Theoretical basis of the study. 


\section{RESEARCH METHODOLOGY}

Quantitative research methods are generally preferred in the natural sciences in order to study natural phenomena whereas qualitative methods typically aim to understand social phenomena that constitute the subject matter of social sciences. Surveys, formal methods and experimental work can be given as examples of quantitative methods. A recent example of quantitative research applied in the area of IS outsourcing has been conducted by Gonzalez, Gasco, and Llopis where they have performed an extensive survey of 4,107 Spanish firms to identify the effects of IS outsourcing determinants (Gonzalez, Gasco \& Llopis, 2010).

The IS outsourcing life cycle involves quite a number of uncertainty parameters and hence it is usually a real-life process which is too complex for survey or quantitative methodologies. Moreover, there are no clear explanations of relations between the context, the processes and their effects on outcomes. Therefore qualitative research based on case studies (Yin, 2009; Runeson \& Höst, 2009) has been preferred in the present study.

The structure of our qualitative research design is depicted in Figure 3.

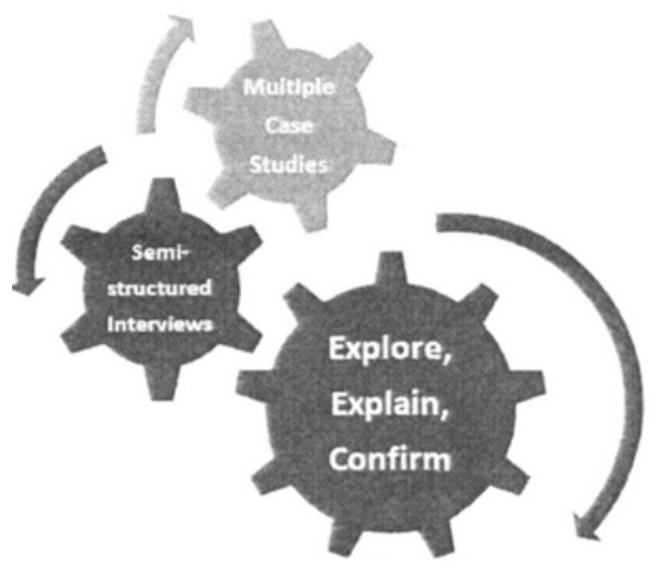

Figure 3. Qualitative research design.

Adopting the multiple-case methodology (Yin, 2009), we first designed an exploratory case with preliminary research questions formed from our conceptual model, viz. determinants of IS outsourcing, four theories from the literature and software development methods. To be more precise, we planned two studies on the same case and used more than one data source, viz. both vendor and client perspectives for the same outsourcing deal. We formulated eight hypotheses as a basis for the rest of the study. Next we designed two validatory cases, first one performed with 
the largest client for Turkish military IS projects and the second one performed with a dominant vendor for health IS projects in Turkey. For these two cases, we performed validatory/confirmatory data analysis where we compared the findings of our initial case without drifting away from the original problem, i.e. IS outsourcing effectiveness.

We had a flexible design allowing the parameters to be modified during the course of the study. We performed semi-structured interviews in all four case studies, i.e. we planned our interviews by starting with a set of introductory questions followed by others, mostly open-ended and with changing sequences depending on our interviewees' responses. For all interviews (except one: Case 2) we were allowed to use a voice recorder. All parties were informed about the research details beforehand in order to maintain initial trust, avoid unethical issues, also enabling them to get prepared prior to the interviews. In addition, transcriptions of the interviews have been sent to the subjects one week after the interviews. The sequence of these four case studies can be seen in Figure 4 and the next section will explain all of them with results and analysis details.

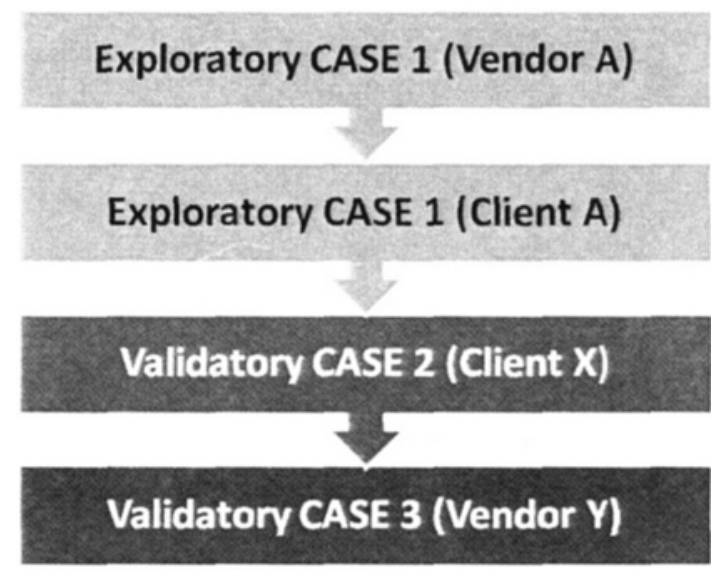

Figure 4. The sequence of multiple cases.

\section{CASE STUDIES}

Analyses and discussions of the following case studies are presented in conformance with the framework established by Runeson \& Höst (2009).

\section{Case 1 (two exploratory studies with Vendor-A and Client-A)}

The first exploratory study in Case 1 has been performed with a national software house (Vendor$A$ ) which has been in the software industry in Turkey for almost twenty years. Having a CMMI-3 certification, Vendor-A is mainly specialized in e-government projects developing products with high-end software techniques like software product lines, XML libraries, and reusable components. The case consisted of the outsourcing of an Electronic Document Management and Archive System (EDMAS). The project being studied started on May 2010 and finished in 7 
months. The scope included the purchasing and customization of vendor's document management Commercial off the Shelf (COTS) product, analysis of sample business processes, definition and realization of these processes in the system, and training. Average number of users of the system was 1200 .

The second study, still as part of Case 1, has been performed with one of the senior IT experts of a public organization (Client- $A$ ) who were Vendor-A's client in the previous study. The interviewee was directly involved in the deal and also works as one of the system support engineers. The unordered set of open-ended questions we prepared for both interviews are given in Appendix B.

Client's need and reasons for outsourcing: Documents in the public sector are very critical and difficult to manage. There are regulations and standards issued by Turkish Prime Ministry and Turkish Standards Institution within the last ten years. Thus, all public organizations have started projects regarding electronic documentation. Before EDMAS, almost all processes were manual and Client-A was able to follow and trace the documents in terms of quantity, source, and destination. EDMAS was acquired for handling official (signed and approved) documents with electronic signature and archiving which was one of the requirements of the government regulations. The main idea behind the project was automation. Client-A has an IT department mainly for system administration type of processes and they do not have sufficient expertise and man power. Moreover, they do not have time for software development since they can hardly manage other tasks. It is clear that the strategic intent of Client- $\mathrm{A}$ is business impact and the main reason for outsourcing is scarcity of expertise. Moreover, Client-A also aimed to enable knowledge transfer (about document management in this particular case. On the other hand, the asset specificity of the outsourced IS (according to TCE) is quite high and although it is a large public organization, Client-A does not have a strong IS department.

Vendor experience: The project was quite a success. Most important of all; Vendor-A had a very strong development team compared to the previous vendors the client had worked with. Moreover, the business analysts of the vendor were very experienced both on partnering with public organizations and on document management know-how. Vendor-A has 16 years of outsourcing experience working with clients from both public and private sector, both national and foreign; not only developing systems from scratch but also selling customizations of COTS products of their own. Vendor-A was the correct organization to work with since both the company and the individuals were experienced in outsourcing (one of the analysts was a transfer from a document management company). In terms of requirements specification process, the vendor continually evaluated users' knowledge. Since the acquired system was one of the vendor's COTS products - customized for Client-A, it saved quite a considerable amount of time. Otherwise it would have cost approximately two full years. Such experienced vendors having infrastructure and frameworks ready to be customized have an advantage to win the tenders for suitable projects. The vendor's outsourcing experience can be measured in terms of number of years the organization has been involved in outsourcing deals in addition to the individual outsourcing experiences of the members of the development team. This approach to vendor 
selection (consideration of the level of outsourcing experience of the vendors) aligns completely with the literature as well.

\section{H1: The level of outsourcing experience of the vendor positively effects vendor success.}

Hereafter, hypotheses based on case evaluations will be presented after discussion of aspects of the cases.

Partnership: Unfortunately some vendors with the 'I can develop anything requested' attitude can be quite informal and this is reflected on the partnership throughout the contract period. Vendor-A enables a long-term strong partnership with the clients by sharing their working model transparently. This way of 'constructing a partnership' rather than 'cost-oriented contracting' agrees with Klepper's (1995) research. The vendor maintains trust by applying negotiations clearly, trying their best to explain the benefits of their working models for the client. They provide 10 to 15 of their own staff to the client for the service period. Special focus should be placed on trust where high level of trust is needed in an outsourcing relationship since it can be viewed as a strategic partnership. Thus partnership quality is proportional to the level of trust between the client and the vendor. This can be determined through shared experiences and should start at the very beginning of the relationship. According to Agency Theory, such a relationship will decrease the information asymmetry between the client and the vendor. Although reference is usually made to an informal (or psychological) contract, trust can be maintained with the real contractual items as well (Sabherwal, 1999). Vural (2004) has referred to this view of trust as a critical success factor in her study of an interesting case of a public IS outsourcing project in Turkey that went through an extreme failure situation, eventually ending successfully.

H2: The level of partnership quality is positively associated with outsourcing success.

H3: The level of trust between the client and the vendor is positively associated with partnership quality.

Risk management: Good vendors would like to finish a project as soon as possible since they allocate resources for it and they want to free them back. Most of the clients do not perform a solid risk analysis in terms of various aspects of the project (e.g. profit-loss analysis). Client-A has not performed such a risk analysis but they have spent sufficient time preparing the RFP. Besides, Vendor-A has won the tender for a lot of reasons including that they made a solid cost and size estimation for the given RFP. Most of the vendors do not do that. Vendor-A has a lot of 'enterprise clients' where such clients do perform such analysis more professionally. An example can be the requested collateral from the vendors during the contract period. The amount of collateral for such enterprise clients can be quite high but this way they do guarantee a lot of issues during this period. Risk management techniques have to be considered and there are two main processes to be taken. First, the clients should proactively identify the risks and then determine the control procedures for these risks. 
H4: Adoption of risk management techniques positively effects outsourcing success.

Vendor-specific results: Vendor-A's perception of third party support is the consulting support provided by university staff. They reside in a techno-park where most of their junior developers continue their graduate studies at the university. They believe such support is crucial for transparency and objectivity and especially public sector clients should heavily consult universities through these techno-parks. Methodologies and maturity models are vital for vendor success; not only for software development but also for other processes. Having a CMMI-3 certification, Vendor-A applies methodologies for tender preparation, purchasing and accounting in addition to software development. They claim that it is impossible to find the time even to prepare a proposal without CMMI compliance. Internal training is also crucial for vendor success. Vendor-A holds formal trainings including CMMI, SPICE, ISO trainings, and various software engineering and project management trainings. They also support junior developers for graduate studies, required that they work on related fields and projects at the university (e.g. software management, XML parsing, CORBA, database transaction management).

H5: Having implemented methodologies and maturity models for software development processes positively effects vendor success.

Vendor-A also adopted intensive use of software product lines (SPL). Hence, they have a competitive edge in the market having rich software component libraries and therefore creating relatively cost-effective COTS products. Reusing these components increases the coefficient of economies of scale and economies of scope with more standardized software products.

H6: Academic support for software developers positively effects vendor success.

H7: Internal training for software developers positively effects vendor success.

Client-specific results: One of the critical success factors is the level of computer-literacy of the client's end-users. Users get used to GUIs where any slight change in these may create problems enabling them to frequently ask help from Systems Support unit. Therefore, end-user training for clients is crucial and Vendor-A provided a very efficient training period for EDMAS. No third party support was used for this project. On the other hand, Government Archives Agency of Turkey - as a regulatory body and acting as a consultant - examined the project and the end product, by means of an auditor.

H8: Internal auditing of the client and user training positively effects outsourcing success.

Data analyses show that the major factor for IS outsourcing effectiveness is a successful vendor. Therefore:

H0: Vendor success positively effects outsourcing success. 
The exploratory model constructed with the hypotheses listed so far is presented in Figure 5. The exploratory case indicates the constructs which increase the effectiveness of IS outsourcing from three perspectives: (i) vendor-side constructs are the outsourcing experience of the vendor, having implemented methodologies and maturity models for software development, academic support and internal training for the developers; (ii) client-side constructs are adoption of risk management techniques, internal auditing and user training; (iii) mutual construct is the level of partnership quality which is directly proportional to the level of trust between the client and the vendor.

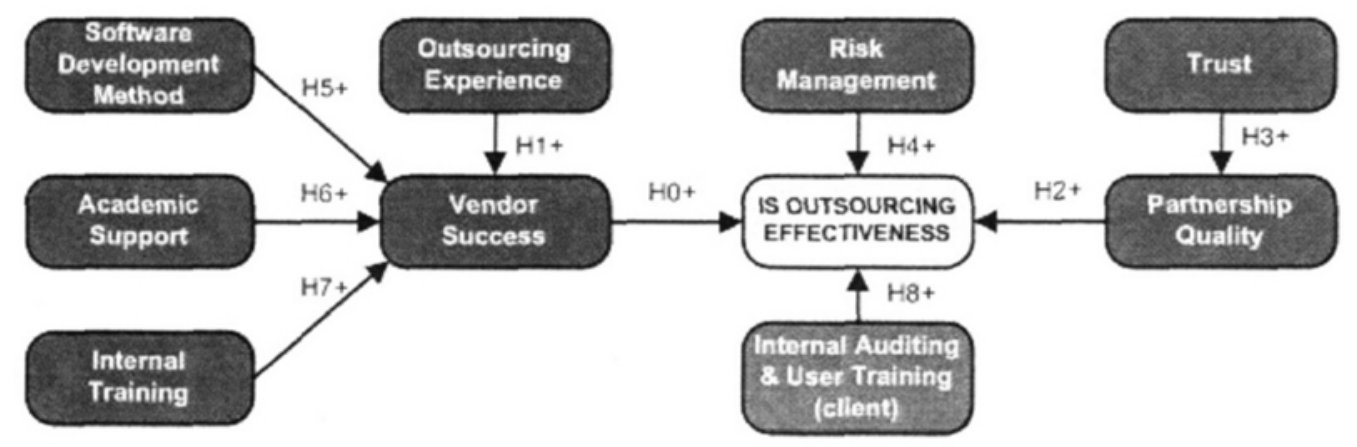

Figure 5. Conceptual Model of IS Outsourcing Effectiveness.

\section{Case 2 (a validatory study with Client-X)}

Client-X which was founded in 1985 is the largest client in national outsourcing projects with the mission of working as an under-secretariat organ for military projects in Turkey. The major function of Client- $X$ is to organize these deals, covering all stages from RFP process to contract negotiation and from contract management to termination. They are mainly working with Turkish vendors encouraging national enterprises with possible cost tolerances. It is specifically stated that Client- $\mathrm{X}$ is not dependent on foreign vendors in software projects and this is an important part of their mission (even though some niche products on imaging, communications, and space technologies may require foreign vendors). Moreover, Client- $X$ usually requires national vendors who are submitting proposals to share $\sim 20 \%$ of the project income with Small and Medium sized Enterprises (SME).

The interviewee claimed that since Client- $X$ is fully responsible for military projects and being the largest client in terms of budget, size, number of system users and stakeholders, there is a total concentration on transparency, public awareness, responsibility and ethical issues. Moreover, the main strategic intent of outsourcing for Client- $X$ is the lack of in-house development expertise. [Validates HYPOTHESES 0 and I]

The interviewee joined Client- $X$ in 1989 at a time when no large-scale software-intensive systems projects were undertaken in Turkey yet. After year 2000 - especially with Client-X initiatives - 
the number of such projects increased rapidly. He believes that CMMI-like maturity models, road maps and standards played an important role in this increase.

Software quality: Besides its benefits for the industry, penetration of SMEs having a share of maximum $20 \%$ of the project income may decrease the level of the quality of the software being developed. Although CMMI certification is usually required for the main contractors, it is not for the sub-contractors (mainly SMEs) since they enact a separate contract with the main contractors (vendors). Currently, there are two CMMI-5 level and three CMMI-3 level vendors in Turkey. Most of the projects are found expensive for those vendors who are not among these major players. On the other hand, Client- $X$ always aims to widely spread the level of quality for the whole industry. They have come up with a solution where they insert an additional contract clause which enables them to audit sub-contractors as well. This mission also minimizes the disadvantage of information asymmetry that Agency Theory mentions. In addition to the quality focus, such an audit option enables Client- $X$ to minimize possible risks. In contrast to the findings of Case 1, where risk management was proposed to be sustained with financial measures, Client$\mathrm{X}$ of Case 2, being a major public client and a regulatory body for defense industry projects, does not revert to financial security measures; instead they apply close control and performance measurement techniques for the same purpose.

[Validates HYPOTHESIS 4]

At the beginning, Client- $X$ required the vendors to follow the traditional waterfall process model due to its robust nature, but in time this strategy evolved in such a way that they prefer the vendors to propose their know-how and methodologies, not to work under pressure and to focus more closely on quality. This shift encouraged those vendors adopting agile development methods to submit proposals as well.

[Validates HYPOTHESIS 5]

Contract duration: Client-X's outsourcing deals are administered according to Public Procurement Law (PPL, 2012) with the major concern of "security". On the other hand, typical contract duration is one to three years due to the rapid change in technologies. If the platform for the applications is also outsourced, this duration can extend to five to seven years. This duration starts when the outsourcing contract becomes effective. If the duration is short, the level of documentation decreases since preparation of technical documents like Software Requirements Specification (SRS), Software Design Description (SDD), Preliminary Design Review (PDR), and Critical Design Review (CDR) requires extensive amount of time. Because of the detailed nature of SRS, main contractors usually need a duration of minimum six months as an adaptation period (the interviewee refers to this as 'the SRS shock').

\section{Case 3 (a validatory study with Vendor-Y)}

Vendor-Y was financially supported by The Scientific and Technological Research Council of Turkey (TÜBITAK) in 2004 for a web-based ERP framework and the interviewee and one of his colleagues have developed this framework. Later on they took leading roles in the development of a Hospital IS at all stages including analysis, design and implementation. Everything was based on the initial framework of 2004. This hospital IS constitutes an e-health platform which 
has been designed and developed within a World Bank financed $R \& D$ project and covers all modules and functionalities required to automate all the business work-flows within the healthcare environment, utilized especially for primary, secondary and tertiary healthcare institutions. Then a larger team developed their second major product, a Document Management System which is a full web based document centric workflow management system that enables enterprises to define, manage and control their business processes in a seamlessly integrated digital and paperless environment. So at the beginning, the interviewee had technical duties including software documentation. In time, he took positions in managerial and administrative positions in Vendor-Y. In short, the interviewee, being one of the partners now, has worked at almost all levels of the organization.

Client profiles: Most clients of Vendor-Y have been from the public sector - they have developed projects for two private hospitals so far, the rest were public health institutions, and they did not expect the vendor to prepare software documents like SRS and SDD. On the other hand, it was an organizational (internal) requirement to prepare them. In general, very few of the clients (public or private) had competent technical units to discuss these issues. Instead, most of them were only dealing with the verification of the functional specifications, i.e. whether they were complete or not.

Remember from the previous case that Client- $X$ from the defense industry is not like that: they require almost all technical documents through the RFP since such clients recruit a lot of military officers who have a BS degree from majors like software and/or computer engineering. Vendor-Y claims that this is an important advantage in terms of talking the same language. One may think that a non-technical client, without technical bias, can deliver the requirements in their most naive form but the vendor thinks that it is a matter of client management. This is a typical example of "vendor power". On the other hand, clients with technical know-how place more functional requirements in the RFP. This enables potential vendors to become more fit and focus more on the proposals. Besides, according to Vendor-Y, RFP is not the major milestone in a project but contract negotiation is. To summarize; public clients in the Turkish health industry are not technically suitable for systems analysis, especially for the requirements specification phase.

Private vs. public: Private clients are more flexible in their purchasing decisions but public clients are obliged to follow the Public Procurement Law (PPL, 2012). On the contrary, private clients select the vendors, then issue the Terms of Reference (TOR), negotiate upon that and perform the acquisition process. (Client- $X$ in the previous case study is an exception among public clients: they have initiatives to select a vendor even if it is not the most cost effective one: viz. staged contracting). In the health industry, through PPL, the client has to select the lowest priced proposal that conforms to all technical requirements. In order to achieve this, they first get opinions of experts from the industry for RFP preparation. Thus; the client might have to work with a vendor who may not be the final nor best choice among possible competitors. Another exception occurs for private clients when the size of the outsourcing deal increases: then there may be a need for a tender also. Vendor-Y's experience with only two private clients shows that these clients did not possess sufficient technical competence. 
Vendor's niche business model: Vendor-Y is not selling its products, but renting them as a service. They usually apply two business models: In model A, they sell it for the first year, and then in the second or third year they start the service and maintenance. In model B, they do not sell at all; they rent it with a monthly subscription fee and they compensate all expenses that may arise as a result of updated regulations performed by The Ministry of Health of Turkey. Vendor- $Y$ currently applies model $B$ for almost all of their public clients. The most beneficial aspect of model $B$ is that the rental duration is not defined, i.e. theoretically infinite. In practice, there exists a contract period - say two or three years - but if the clients are satisfied then they definitely extend the contract - some hospitals who started a deal in 2004 are still clients of Vendor-Y. The main reason for adapting such a model is that the specifications of software systems in the health industry are subject to change at an annual rate of $30 \%$. It is totally nonsense for a public hospital to buy an "as-is" IS since in a year or two it may be idle. We may view it similar to the SaaS (Software as a Service) model in cloud computing with a big difference though: Vendor-Y places a number of service staff in each hospital. Thus, service is provided on-site all the time. Almost all clients of Vendor- $Y$ had another hospital IS before Vendor-Y's product but with this niche business model, Vendor-Y has captured almost $95 \%$ of the whole market.

Customer intimacy (partnership): The interviewee is of the opinion that: "number one determinant is communication". Business, with its determining local characteristics, is quite different from what is being taught, based mainly on global principles, at the university. Success rate is directly proportional with how good you manage people and this can be achieved with knowledge and communication skills - bringing a competitive edge just like Sabherwal's 'identification-based trust'. One important parameter of these communication channels is ways of socializing with their clients with events like dinners, functions, etc.

[Validates HYPOTHESES 2 and 3]

Third party support: Since Vendor-Y mainly contracts with public clients, usually there are no conflicting issues since for public deals the contract structure is pre-determined by law. Therefore there is no need for a third party 'audit'. The vendor may suggest a consultant (probably academic) for the client only if the client requests the potential vendors' ideas. These are generally related to the quality standards (e.g. ISO9000). On the other hand, for some deals, potential vendors may get a certain certification from the Ministry of Health which acts as the regulatory body for these outsourcing deals.

[Validates HYPOTHESES 6 and 7]

In-house or outsource? In Turkey, some hospitals did not have an automated hospital information system until the mid-2000s. For those who had a hard time making an outsourcing decision, Vendor-Y's argument was clear enough: "for a client - even if they performed a costbenefit analysis which favored in-house development - it was impossible to obtain the vendor's know-how and best practices. It would be terribly costly in the long run." Clearly, it is a win-win situation in a quite wild and competitive market - there were 80 potential vendors in this industry in 2005 when Vendor-Y penetrated the market. 
Training and BPR: An important requirement of Vendor-Y's business model is continuous training sessions for hospital users. Naturally and as an important asset for the vendor, Vendor- $Y$ applies $B P R$ for these clients - constant tuning during processes; e.g. billing process. In general, hospitals are hiring 10 to 200 project-based data operators depending on the hospital size and in time, they may shift some of the talented staff to other internal IT positions. [Validates HYPOTHESIS 8]

University hospitals: Some universities having a school of medicine develop these systems for their hospitals by forming a foundation and hiring software engineers for development purposes. At the end of the day, they cannot compete with a software house since such vendors provide richer and far more usable software libraries and components. Although such in-house developed systems are very client-specific, they cannot provide the same quality since they are not forced to compete with external vendors. As TCE and RBV suggest, hospital IS have high asset-specificity and highly firm-specific, i.e. considered as core competencies of the clients (hospitals) rather than commodities and therefore usually being outsourced rather than being built in-house.

Software development methods: Vendor-Y applies traditional waterfall methodologies. Moreover, they heavily make use of product lines and reusable component libraries together with capabilities of MS Visual Studio . Net ${ }^{\circledR}$. Vendor-Y does not apply agile software development methods since their corporate culture is against it and moreover, usually the public clients have the time and the money to afford longer development cycles. They do not have CMMI certification but they do apply their own model where they measure four basic metrics: (i) lines of code (LOC), (ii) estimated duration, (iii) success rates of test results, (iv) whether deadlines are met or not. They track the performance of their developers within the scope of these metrics. Vendor-Y does not make use of well-known tools in the market since they have designed their own software development process.

Rewards/penalties: In the Turkish software industry, unlike many other global settings, usually there are no rewards but there are penalties. Most of the penalties explicitly stated in the RFPs are due to missed deadlines and unsatisfied requirements. On the other hand, cultural influences are seen to dominate: there can be three different decisions from two different experts who comment on RFP for public deals and sometimes such penalties can be ignored. Similar comments have been made by both parties in the exploratory case (Case 1). We have not hypothesized this parameter back then for two reasons: (a) the outsourcing literature is not abundant on such cultural influences and (b) the interviewees did not emphasize this issue as much as others. Since Case 3 is a validatory study, the relation between the number of penalty clauses in outsourcing contracts and partnership quality is considered to deserve future research, in the specificity of the Turkish, and possibly other similar cultural contexts.

Subcontracting: Vendor-Y had a negative experience with subcontracting. The project was again a hospital IS, namely an ERP system with 30 different modules. They subcontracted 3 of those modules which consisted of the Laboratory IS to another vendor due to technical and financial reasons. They experienced a lot of problems with the subcontractor where even the client felt the problem as well. They formally issued a warning nine months prior to the termination of the 
subcontract and eventually had to change subcontractor. In similar situations, the client may misunderstand the whole issue as "a change to the product" which may end up as a failure of the whole outsourcing deal. The literature on subcontracting is quite rich. Moreover, Client-X of Case 2 encourages it with a nation-wide mission where SMEs should be involved and play an important role in such deals. Since Case 3 is a validatory study, the relation between subcontractor success and vendor success is also considered to deserve future research. 


\section{VALIDITY THREATS FOR THE CASE STUDIES}

The validity of a research is determined in terms of the objectivity and trustworthiness of the results and data analyses. The researchers should not be subjective (or biased) about the outcomes of the study and the results should be assumed to be true to a large extent. The validity issue should be studied throughout the research but it is more convenient to evaluate it at the end of the analysis phase. For this evaluation Runeson \& Höst (2009) suggest a classification scheme that consists of construct validity, internal validity, external validity, and reliability. Below, we discuss the threats we have perceived regarding the validity of our research, and our means and measures to mitigate those threats, according to this classification.

Construct validity: The operational measures we studied represent our thoughts and claims within the framework of the literature and they correspond to the research questions we started with. The tools we used to come up with our research constructs were the interviews and we used verbal as well as documented descriptions and clarifications to ensure that the interviewees' and researcher's interpretations of these constructs were identical.

Internal validity: Outsourcing is a social and non-deterministic process due to the vast amount of uncertainty that affects almost all stages in the life cycle. Although the steps in IS outsourcing life cycle are clear and well defined, some of the determinants like contract management and relationship management and risk analysis are totally dependent on economic, cultural, and even political contexts. Therefore, even if we believe we performed well in analyzing the interrelationships between the effectiveness factors, we cannot guarantee the completeness of these factors for the four case studies we performed. Hence to enhance internal validity, first an extensive literature survey was performed to constitute the basis of our hypotheses, and then, throughout the research, we were explicitly open to novel instances, ideas and interpretations.

External validity: The subjects (in terms of organizations and the interviewees) were selected conscientiously for the case studies, and they are all significant actors representing the industry in a powerful aspect being major clients and vendors for IS outsourcing deals (one of the most experienced vendors in the software industry, the leading public clients in defense industry also acting as a regulatory body, and another vendor being the industry leader in health information systems). Therefore we can claim that our findings are relevant for other cases (of other researchers) to a large extent. All case studies were carried out in Turkey, and cultural issues were openly considered whenever they arose. Business practices and project characteristics, however, generally conform to international norms, hence providing a fairly acceptable level of generalizability of findings. Full theoretical and universal validity, however, is neither claimed, nor possible, and as with many instances of qualitative research, our model constitutes nothing more than a set of hypotheses validated in a certain context.

Reliability: We completed the core of the literature survey in almost a year and constantly updated it throughout the research. Thus, we believe that it was one of the solid surveys made recently in the field of IS outsourcing. Therefore, if another researcher conducts a similar study in 
the near future, the results would likely turn out to be similar. On the other hand, in the long run we cannot guarantee the same since regulations, technologies, and communication channels are changing very fast and such dynamics would definitely effect IS outsourcing processes.

Final note: We have started with a preliminary case (Case-1) with exploratory purposes and constructed our main hypotheses based on this case study. Although we have performed two more validatory case studies with leading organizations, we believe that we could have increased the number of preliminary cases if time would permit because it is evident that there are many other factors still waiting to be explored. Some of these are mentioned in the following section.

\section{CONCLUSION}

Summary: The objective of our research was to explore IS outsourcing experiences, factors that affect the success of such outsourcing deals, and how these factors are related to the outcome. We have planned the cases and prepared our research design based on four theories and major software development methods together with the determinants of a typical outsourcing life cycle.

At the end of the exploratory case studies we have come up with nine hypotheses which were then considered in validatory cases for designing a qualitative model answering the following questions from the clients' perspectives: "Have we achieved the expected cost/quality?" and "Has this deal contributed to my IT maturity and business processes?" Although an a-posteriori model is developed, it will also work as a decision model in light of best practices for future outsourcing deals for clients and vendors. Both research questions have been answered in the form of a conceptual model that consists of ten determinants of IS outsourcing effectiveness and, nine relationships between pairs of those determinants.

Contributions: The exploratory case has contributed to our research from three perspectives: (a) initial infrastructure of our effectiveness model is formed, (b) the critical success factors of the effectiveness of IS outsourcing, initially created through an extensive literature review, are formed to be used for the following validatory cases, (c) the formation and correlation of theoretical foundations and effects of IS development approaches to the determinants of a typical outsourcing life cycle is set. This effectiveness model can be used for other researchers since it actually is a summary of the IS outsourcing literature. It may even be used as a roadmap for quantitative research (e.g. survey methods).

The validatory cases have contributed to our research mainly from two perspectives: (a) the largest national client's opinions on outsourcing was quite important since their deals are proportional to a large share of the total number of deals in the industry, (b) we realize that additional determinants of IS outsourcing like sub-contracting and contract penalty items can be studied with an enhanced future model. On the other hand, it has been confirmed by the interviewees that for public IS outsourcing deals, vendors who implement process improvement models - mainly CMMI - have a visible advantage as regards the bidding results. 
Moreover, the validatory Case 3 has contributed to our research from a couple of perspectives: (a) contract negotiation may be more important than the RFP in a social and cultural setting such as the Turkish one, (b) when public clients' know-how is quite low, communication and partnership are the major parameters, (c) a different model of IS outsourcing where the whole deal can be based on service fees is seen to be quite beneficial for both sides in the health industry, (d) without having a CMMI like certification, a vendor may lead the industry (depending on the industry dynamics), and (e) subcontracting without prior experience may involve high risks.

As a summary, we believe that this research has contributed to IS outsourcing literature by providing a novel and comprehensive effectiveness model based on a survey of the literature in terms of IS outsourcing determinants, a selective set of related theories and effects of software development approaches. This model highlights the importance of applying a well-defined (preferably standardized) software development method for the vendors to gain competitiveness in the outsourcing market. By the help of this model, we hope that the clients can assess their outsourcing performance and re-evaluate their business and management strategies.

Limitations: The interviews and the findings show that due to the nature of the outsourcing process, the existence of uncertainty is the major limitation for all similar types of research. Cultural, political and economical factors, all together, cause and form the level of uncertainty. Especially for the public clients where in-house experience is quite low, governmental regulations, budget and resource allocation, and bureaucracy created by deep organizational hierarchies are the main reasons for uncertainty. Due to this reason, the completeness and continuity of the relations and constructs we formed for the effectiveness model may not be sustained all the time but we believe they remain to be the critical success factors most of the time.

Although we believe that the cases (the organizations and the subjects we interviewed) are studied after a careful selection process, the interpretations and results may contain some level of bias since all of the cases were success cases. The interviewees may have a positive interpretation of the outsourcing experiences in their organization.

The industry shifts, emerging IS development methods, technological advancements and all other types of dynamics may cause similar research to conclude with slightly different results in the long run. On the other hand, in the near future, we believe similar results can be obtained within the same context by other researchers.

Future Research Directions: In this research, success factors are theoretically studied. If confidentiality issues permit, future studies may include failure (negative) cases so that a different perspective on the final qualitative model can be formed. We believe that studying such cases will contribute to the effectiveness model and in return, will contribute to current and potential clients and vendors for better benchmarking and regulating their business processes in light of lessons learned from these cases. 
Extending the study to multi-cultural settings to establish a more comprehensive assessment of global and local aspects of the issue of modeling, assessing or ensuring IS outsourcing effectiveness would also definitely contribute to this field. With the advancements in internet infrastructure and web technologies, cloud solutions like Software as a Service (SaaS) are becoming very popular. This way clients obtain services from the vendors through the cloud (the internet). We believe that such advancements may change procurement models in outsourcing. This form of service outsourcing can be integrated to our effectiveness model in the future.

Looking at the results of Case 2 and Case 3 on making use of sub-contractors, sufficient thought should be devoted to the following dilemma in order to better evaluate the pros and cons of subcontracting:

- "SMEs should be encouraged to benefit from corporate software houses' know-how and best practices and hence contribute to the growth of software industry."

- "A certain maturity level is required from the main contractor but not from the subcontractors and this may lead to some vulnerabilities in the level of software quality."

Effects of subcontracting success on vendor success and the relation between contract penalty items and partnership quality may be studied in future research studies.

As a final remark, a quantitative research like a comprehensive survey can be combined with case studies to test and validate most of the (quantifiable) hypotheses presented. This would definitely enhance the generalizability and maturity of the presented model.

\section{REFERENCES}

1. Al-Salti, Z. \& Hackney, R. (2011). Factors impacting knowledge transfer success in information systems outsourcing. Journal of Enterprise Information Management, 24(5), 455-468.

2. Alvarez-Suescun, E. (2007). Testing resource-based propositions about IS sourcing decisions. Industrial Management \& Data Systems, 107(6), 762-779.

3. Aubert, B.A., Rivard, S., \& Patry, M. (2004). A transaction cost model of IT outsourcing. Information \& Management, 41(7), 921-932.

4. Aubert, B.A., Beaurivage, G., Croteau, A., \& Rivard, S. (2008). Firm strategic profile and IT outsourcing. Information Systems Frontiers, 10(2), 129-143.

5. Aubert, B.A., Houde, J.F., Patry, M., \& Rivard, S. (2012). A multi-level investigation of information technology outsourcing. Journal of Strategic Information Systems, in press.

6. Barthelemy, J. \& Geyer, D. (2004). The determinants of total IT outsourcing: An empirical investigation of French and German firms. Journal of Computer Information Systems, 44(3), 91-97.

7. Beasley, M., Bradford, M., \& Dehning, B. (2009). The value impact of strategic intent on firms engaged in information systems outsourcing. International Journal of Accounting Information Systems, 10(2), 79-96. 
8. Bryson, N. \& Ngwenyama, O.K. (2000). Structuring IS outsourcing contracts for mutual gain: An approach to analyzing performance incentive schemes. Journal of the Association for Information Systems, 1(9), 1-41.

9. Chaudhury, A., Nam, K., \& Rao, H.R. (1995). Management of information systems outsourcing: A bidding perspective. Journal of Management Information Systems, 12(2), 131-159.

10. Cheon, M.J., Grover, V., \& Teng, J.T.C. (1995). Theoretical perspectives on the outsourcing of information systems. Journal of Information Technology, 10(4), 209-219.

11. Clements, P., \& Northrop, L. (2002). Software Product Lines: Practices and Patterns, USA: Addison Wesley, SEI Series in Software Engineering.

12. Cronk, J. \& Sharp, J. (1995). A framework for deciding what to outsource in information technology. Journal of Information Technology, 10(4), 259-267.

13. Dibbern, J., Goles, T., Hirschheim, R., \& Jayatilaka, B. (2004). Information systems outsourcing: A survey and analysis of the literature. DATA BASE for Advances in Information Systems, 35(4), 6-102.

14. Dibbern, J., Chin, W.W., \& Heinzl, A. (2012). Systemic determinants of the information systems outsourcing decision: A comparative study of German and United States firms. Journal of the Association for Information Systems, 13(6), 466-497.

15. DiRomualdo, A. \& Gurbaxani, V. (1998). Strategic intent for IT outsourcing. MIT Sloan Management Review, 39(4), 67-80.

16. Dobrzykowski, D., Tran, O. \& Tarafdar, M. (2010). Value co-creation and resource based perspectives for strategic sourcing. Strategic Outsourcing: An International Journal, 3(2), 106-127.

17. Espino-Rodriguez, T.F. \& Rodriguez-Diaz, M. (2008). Effects of internal and relational capabilities on outsourcing: An integrated model. Industrial Management \& Data Systems, 108(3), 328-345.

18. Feeny, D., Lacity, M., \& Willcocks, L.P. (2005). Taking the measure of outsourcing providers. MIT Sloan Management Review, 46(3), 40-49.

19. Gonzalez, R., Gasco, J., \& Llopis, J. (2010). Information systems outsourcing: An empirical study of success factors. Human Systems Management, 29(3), 139-151.

20. Goo, J. \& Huang, C.D. (2008). Facilitating relational governance through service level agreements in IT outsourcing: An application of the commitment-trust theory. Decision Support Systems, 46(1), 216232.

21. Grover, V., Cheon, M.Y., \& Teng, J.T.C. (1996). The effect of service quality and partnership on the outsourcing of information systems functions. Journal of Management Information Systems, 12(4), 89-116.

22. Gulla, U. \& Gupta, M.P. (2012). Deciding the level of information systems outsourcing: Proposing a framework and validation with three Indian banks. Journal of Enterprise Information Management, 25(1), 28-59.

23. Hazzan, O. \& Dubinsky, Y. (2008). Agile Software Engineering. London: Springer.

24. Heckman, R. (1999). Organizing and managing supplier relationships in information technology procurement. International Journal of Information Management, 19(2), 141-155. 
25. Heiskanen, A., Newman, M., \& Eklin, M. (2008). Control, trust, power, and the dynamics of information system outsourcing relationships: A process study of contractual software development. Journal of Strategic Information Systems, 17(4), 268-286.

26. Hu, Q., Saunders, C., \& Gebelt, M. (1997). (Research report) Diffusion of information systems outsourcing: A reevaluation of influence sources. Information Systems Research, 8(3), 288-301.

27. Hyde, K. \& Wilson, D. (2004). Intangible benefits of CMM-based software process improvement. Software Process Improvement Practice, 9(4), 217-228.

28. Jurison, J. (1995). The role of risk and return in information technology outsourcing decisions. Journal of Information Technology, 10(4), 239-247.

29. Kern, T. \& Blois, K. (2002). Norm development in outsourcing relationships. Journal of Information Technology, 17(1), 33-42.

30. Kern, T., Willcocks, L.P., \& van Heck, E. (2002). The winner's curse in IT outsourcing: Strategies for avoiding relational trauma. California Management Review, 44(2), 47-69.

31. Kim, K.K., Shin, H.K., \& Lee, M.H. (2010). The influence of partner knowledge complementarities on the effectiveness of IT outsourcing. Journal of Organizational Computing and Electronic Commerce, 20(3), 213-233.

32. Kim, S. \& Chung, Y. (2003). Critical success factors for IS outsourcing implementation from an interorganizational relationship perspective. Journal of Computer Information Systems, 43(4), 81-90.

33. Kishore, R., Rao, H.R., Nam, K., Rajagopalan, S., \& Chaudhury, A. (2003). A relationship perspective on IT outsourcing. Communications of the $A C M, 46(12), 86-92$.

34. Klepper, R. (1995). The management of partnering development in IS outsourcing. Journal of Information Technology, 10(4), 249-258.

35. Krishnamurthy, K., Jegen, D., \& Brownell, B. (2009). Strategic out-tasking: Creating "win-win" outsourcing partnerships. Information \& Management, 46(1), 42-51.

36. Lacity, M.C. \& Hirschheim, R. (1993). The information systems outsourcing bandwagon. MIT Sloan Management Review, 35(1), 73-86.

37. Lacity, M.C., Khan, S.A., \& Willcocks, L.P. (2009). A review of the IT outsourcing literature: Insights for practice. Journal of Strategic Information Systems, 18(3), 130-146.

38. Lee, J. \& Kim, Y. (1999). Effect of partnership quality on IS outsourcing success: Conceptual framework and empirical validation. Journal of Management Information Systems, 15(4), 29-61.

39. Lee, J. (2001). The impact of knowledge sharing, organizational capability and partnership quality on IS outsourcing success. Information \& Management, 38(5), 323-335.

40. Lee, J., Heng, C.S., \& Lee, J. (2009). Multi-vendor outsourcing: Relational structures and organizational learning from a social relation perspective. Proceedings of ICIS, the International Conference of Information Systems, Phoenix, Arizona, Paper 71.

41. Linden, F., Schmid, K., \& Rommes, E. (2007). Software Product Lines in Action: The Best Industrial Practice in Product Line Engineering, Berlin: Springer.

42. Loh, L. \& Venkatraman, N. (1992). Diffusion of information technology outsourcing: Influence sources and the Kodak effect. Information Systems Research, 3(4), 334-358. 
43. McClure, C. (1995). Model-Driven Software Reuse, Practicing Reuse Information Engineering Style.

44. Meso, P. \& Smith, R. (2000). A resource-based view of organizational knowledge management systems. Journal of Knowledge Management, 4(3), 224-234.

45. Mili, H., Mili, F., \& Mili, A. (1995). Reusing software: Issues and research directions. IEEE Transactions on Software Engineering, 21(6), 528-561.

46. Moon, J., Swar, B., Choe, Y.C., Chung, M., \& Jung, G.H. (2010). Innovation in IT outsourcing relationships: Where is the best practice of IT outsourcing in the public sector? Innovation: Management, Policy \& Practice, 12(2), 217-226.

47. Nam, K., Rajagopalan, S., Rao, H.R., \& Chaudhury, A. (1996). A two-level investigation of information systems outsourcing. Communications of the $A C M, 39(7), 36-44$.

48. Oh, W.O., Gallivan, M.J., \& Kim, J.W. (2006). The market's perception of the transactional risks of information technology outsourcing announcements. Journal of Management Information Systems, 22(4), 271-303.

49. Oza, N.V., Hall, T., Rainer, A., \& Grey, S. (2006). Trust in software outsourcing relationships: An empirical investigation of Indian software companies. Information and Software Technology, 48(5), 345-354.

50. Palvia, P.C. (1995). A dialectic view of information systems outsourcing: Pros and cons. Information \& Management, 29(5), 265-275.

51. Pinnington, A. \& Woolcock, P. (1997). The role of vendor companies in IS/IT outsourcing. International Journal of Information Management, 17(3), 199-210.

52. PPL (2012). Public Procurement Law. Republic of Turkey, Public Procurement Authority. Retrieved from http://wwwl.ihale.gov.tr/english/4734_English.pdf

53. Runeson, P. \& Höst, M. (2009). Guidelines for conducting and reporting case study research in software engineering. Empirical Software Engineering, 14(2), 131-164.

54. Sabherwal, R. (1999). The role of trust in OISD projects. Communications of the ACM, 42(2), 80-87.

55. Sashikala, P. (2010). Competitive advantage using information systems outsourcing: A framework. The IUP Journal of Systems Management, 8(1), 15-28.

56. Satther, H.S. \& Gottschalk, P. (2008). Maturity in IT outsourcing relationships: An exploratory study of client companies. Industrial Management \& Data Systems, 108(5), 635-649.

57. Shi, Z., Kunnathur, A.S., \& Ragu-Nathan, T.S. (2005). IS outsourcing management competence dimensions: Instrument development and relationship exploration. Information \& Management, 42(6), 901-919.

58. Tan, C. \& Sia, S.K. (2006). Managing flexibility in outsourcing. Journal of the Association for Information Systems, 7(4), 179-206.

59. Vural, I. (2004). Success Factors in Public Information Systems Outsourcing: A Case Study. MSc Thesis, Informatics Institute, Middle East Technical University, Ankara, Turkey.

60. Willcocks, L.P. \& Lacity, M.C. (1995). Information systems outsourcing in theory and practice. Journal of Information Technology, 10(4), 203-207. 
61. Willcocks, L.P. \& Lacity, M.C. (1999). IT outsourcing in insurance services: Risk, creative contracting and business advantage. Information Systems Journal, 9(3), 163-180.

62. Williamson, O.E. (1979). Transaction-cost economics: The governance of contractual relations. Journal of Law and Economics, 22(2), 233-261.

63. Yin, R.K. (2009). Case Study Research: Design and Methods, Fourth Edition. CA: Sage Publications. 


\section{APPENDIX A \\ Operational Definition of the Parameters of the Conceptual Model}

Table A.1: Operational definition of the determinants of IS outsourcing life cycle.

\begin{tabular}{|c|c|}
\hline Determinant & Related literature and notes \\
\hline Strategic intent & $\begin{array}{l}\text { Strategic intent can be defined as the major reason(s) of outsourcing for a client. It } \\
\text { includes the need for such an IS and answers the question 'why can't we build it in- } \\
\text { house?'. According to DiRomualdo \& Gurbaxani (1998), strategic intents can be studied } \\
\text { in three categories: (i) improving IS, (ii) creating a business impact, and (iii) commercial } \\
\text { exploitation. Beasley et al. (2009) conclude that strategic intent and the firm size is } \\
\text { correlated: large firms do not outsource with the intention of cost minimization. The } \\
\text { strategic role of IS may or may not result in outsourcing (Cronk \& Sharp, 1995). The } \\
\text { effects of systemic factors and cultural contexts can be found in Dibbern et al. (2012). } \\
\text { Another type of stategic intent is transferring knowledge (Al-Salti \& Hackney, 2011). }\end{array}$ \\
\hline Degree of outsourcing & $\begin{array}{l}\text { Degree of outsourcing is defined as the scope of outsourcing in terms of the client's IS } \\
\text { budget: deals corresponding to } 80 \% \text { or more of the budget is called total, if within the } \\
\text { range of } 15 \% \text { to } 25 \% \text { is called selective (or partial) outsourcing (Willcocks \& Lacity, } \\
\text { 1999). If the client has a strong IT department then selective outsourcing is preferred } \\
\text { (Barthelemy \& Geyer, 2004). According to Gulla \& Gupta (2012) managers should } \\
\text { carefully analyze outsourcing drivers which in return effects the degree of outsourcing. }\end{array}$ \\
\hline Vendor selection & $\begin{array}{l}\text { Vendor selection is the most important stage of outsourcing life cycle since it is the initial } \\
\text { step of a strategic partnership. Pinnington \& Woolcock (1997) studied the effects of } \\
\text { vendor selection to outsourcing relationship between the clients and vendors intwo } \\
\text { categories, viz. contextual and active relationships. Vendor selection should not be } \\
\text { performed according to vendor's resources and assets but should focus more on } \\
\text { infrastructure and methodologies (Feeny et al., 2005). Consulting to third parties is quite } \\
\text { common in vendor selection process. The due-diligence process (process to test if a } \\
\text { vendor has enough resources) and winner's curse (a situation when the vendor who wins } \\
\text { the bidding systematically bids above the actual value of the IS and hence incurs losses) } \\
\text { are two important factors to be studied in the vendor selection process (Kern et al., 2002). } \\
\text { The importance of vendor experience and bidding power for the vendor selection process } \\
\text { is studied by Kim \& Chung (2003) and Chaudhury et al. (1995). }\end{array}$ \\
\hline $\begin{array}{l}\text { Contract and relationship } \\
\text { management }\end{array}$ & $\begin{array}{l}\text { Contract management is defined as mutually managing the contract clauses and } \\
\text { contractual obligations. Initial phase of contract management is the contract negotiation. } \\
\text { Relationship management, on the other hand, is managing the application of these contract } \\
\text { items through human relations and effective communication within cultural contexts. The } \\
\text { literature is extensively rich on this issue of outsourcing. Satther \& Gottschalk (2008) } \\
\text { emphasize the importance of resources allocated by both parties only for relationship } \\
\text { management since it is the core of a strategic and long-term partnership. Similarly, Bryson } \\
\& \text { Ngwenyama (2000) studied the effectiveness of incentive schemes enabling a fruitful } \\
\text { and solid partnership. According to Klepper (1995), sufficient effort and budget should be } \\
\text { spent for communication channels, meetings and discussions. Effectiveness factors for a } \\
\text { healthy relationship include knowledge acquisition, methodologies and business process } \\
\text { reengineering (BPR). Differences between working with single and multiple vendors are } \\
\text { studied by Lee et al. (2009). Sabherwal (1999) mentions that trust - although involves risk } \\
\text { - is a very important factor in outsourcing deals and should be maintained throughout the }\end{array}$ \\
\hline
\end{tabular}


whole process (Oza et al., 2006).

Table A.2: Operational definition of the theories effecting IS outsourcing process.

\begin{tabular}{|c|c|}
\hline Theory & Related literature and notes \\
\hline $\begin{array}{l}\text { Transaction cost } \\
\text { economics (TCE) }\end{array}$ & $\begin{array}{l}\text { TCE is mainly used to determine the make-or-buy decision (Williamson, 1979). In other } \\
\text { words it is the theoretical foundation behind strategic intent and degree of outsourcing. } \\
\text { Asset specificity is the main driver for the application of TCE upon outsourcing (Nam et } \\
\text { al., 1996). Large clients with strong IS departments may not favor outsourcing. Moreover, } \\
\text { clients prefer outsourcing those IS functions having low uncertainty (Aubert et al., 2004). }\end{array}$ \\
\hline Agency theory (ACT) & $\begin{array}{l}\text { ACT studies the information asymmetry between the client and the vendors. Similar to } \\
\text { TCE, important factor of uncertainty which is a result of this information asymmetry is the } \\
\text { main concern in ACT (Dibbern et al., 2004). What ACT suggests is the goals and } \\
\text { requirements of the client and the vendor should match. Therefore it is highly a } \\
\text { relationship (and consequently a contract) related theory (Cheon et al., 1995). Agency } \\
\text { costs increase with high uncertainty, high risk aversion, low level of vendor behavior, low } \\
\text { outcome measurability, and long duration of contract relationship (Kim et al.,2010). }\end{array}$ \\
\hline $\begin{array}{l}\text { Resource dependency } \\
\text { theory (RDT) }\end{array}$ & $\begin{array}{l}\text { RDT proposes that companies exchange resources to reduce uncertainty (Oh et al., 2006). } \\
\text { Application of RDT on IS outsourcing can be explained as the exchange of mutual } \\
\text { benefits between the clients and vendors. There are various factors determining this } \\
\text { dependency such as resource value, number of potential vendors and the switching cost } \\
\text { between vendors (for a failure case) and the level of dependency is directly proportional to } \\
\text { the number of contract clauses. Lacity \& Willcocks (1995, 1998) studied IS outsourcing in } \\
\text { terms of RDT: short-term contracts are more effective due to the minimized cost of vendor } \\
\text { monitoring. }\end{array}$ \\
\hline $\begin{array}{l}\text { Resource based view } \\
\text { (RBV) }\end{array}$ & $\begin{array}{l}\text { RBV studies the strategic important of resources an organization possesses (Meso \& } \\
\text { Smith, 2000). If this possession is sustained, the client gains power in the business domain } \\
\text { (Espino-Rodriguez et al., 2008). A client can diversify its resources via outsourcing. In the } \\
\text { long run, such a diversification may increase the number of core competencies of the } \\
\text { organization which in return prevents the organization to outsource similar resources } \\
\text { (some sort of a cycle). Similar to TCE, RBV can be applied to determine which resources } \\
\text { to be outsourced. Alvarez-Suescun (2007) have researched such decision models. }\end{array}$ \\
\hline
\end{tabular}


Table A.3: Operational definition of the IS development approaches effecting IS outsourcing process.

\begin{tabular}{|c|c|}
\hline $\begin{array}{l}\text { IS development } \\
\text { approach }\end{array}$ & Related literature and notes \\
\hline $\begin{array}{l}\text { Process improvement } \\
\text { models }\end{array}$ & $\begin{array}{l}\text { Process improvement models are frameworks to manage, measure, and monitor software } \\
\text { development processes and they can be used to benchmark software vendors against } \\
\text { others to achieve lower cost and higher quality results (Hyde \& Wilson, 2004). Capability } \\
\text { Maturity Model Integration (CMMI) stands as a primer among the well-known models in } \\
\text { terms of its detailed context and widespread use. There are some key success factors that } \\
\text { clients need; meeting the expected cost and quality benefits, preparation of a well-defined } \\
\text { contract, having an efficient interface with the vendor, and ensuring continuous } \\
\text { effectiveness. Process improvement models can provide them. }\end{array}$ \\
\hline $\begin{array}{l}\text { Agile development } \\
\text { approaches }\end{array}$ & $\begin{array}{l}\text { Agile methods initially accepts the change in user requirements which then can be } \\
\text { iteratively incorporated into the product (Agile Manifesto). This enables a potential } \\
\text { product release ready at any time. Agile methods focuses on people and communication, } \\
\text { working software, collaboration, and adapting to change instead of processes, extensive } \\
\text { documentation, and contract negotiation. With agile teams, clients are delivered frequent } \\
\text { working parts of the system on a regular basis which brings flexible and variable payment } \\
\text { methods for the client (Hazzan \& Dubinsky, 2008). Outsourcing heavily relies on } \\
\text { documentation in terms of contractual notions which slows down this production. Agile } \\
\text { methods are advantageous for projects having weak scope definitions and they strengthen } \\
\text { the partnership through co-operative efforts on both parties and hence building longer- } \\
\text { term relationships for future deals. }\end{array}$ \\
\hline Software reuse & $\begin{array}{l}\text { Software reuse can be defined as developing software systems using existing software } \\
\text { components (Mili et al., 1995). Software reuse aims cost and time minimization while } \\
\text { increasing quality. Logically, cost of an initial investment for the process is usually high } \\
\text { but the expected pay-off during the whole development process overcomes this cost } \\
\text { easily. With the developments in reuse approach, organizational views that effect the } \\
\text { process have evolved and a new concept called a Software Product Line (SPL) has } \\
\text { emerged during late } 90 \text { s (Clements \& Northrop, 2002). Clients experience the benefit of } \\
\text { acquiring IS as a product line consisting of software systems with commonalities in terms } \\
\text { of minimized costs, fast delivery time, and simplified trainings. Evolution of SPL, major } \\
\text { benefits and important case studies can be studied in Linden et al. (2007). }\end{array}$ \\
\hline
\end{tabular}




\section{APPENDIX B \\ Case 1 Interview Questions}

The unordered set of open-ended questions prepared for both interviews of CASE 1 are as follows:

Vendor-A:

- What are the strategic intents of outsourcing for your clients?

- Do they outsource their IS completely or just some important modules of them?

- $\quad$ For the tenders you win, what are the main reasons for being a selected vendor?

- How do you build a partnership with your clients during the contract period?

- Which software development methods do you apply?

\section{Client-A:}

- What was your strategic intent of outsourcing for this system?

- Did you outsource the system completely or just some important modules of it?

- Why did you select Vendor-A for this deal?

- How did you build a partnership with Vendor-A during the contract period?

- How specific - as an asset - were the outsourced system (EDMAS) for your organization?

- Have you faced any uncertainty during the contract period?

- What benefits did you get from the deal you made with Vendor-A? 


\section{Erkan Uçar}

Dr. Erkan Uçar graduated from the Computer Engineering Department of Bilkent University, Ankara, Turkey, in 1990. He finished his MSc work at the same department in 1993. He got his PhD in Information Systems from the Middle East Technical University Ankara, Turkey, in 2012. $\mathrm{He}$ is an instructor and chairman of the Computer Technology and Information Systems Department of Bilkent University. His research interests are information systems, data structures and artificial intelligence.

\section{Semih Bilgen}

Dr. Semih Bilgen graduated from the Electrical and Electronics Engineering (EEE) Department of the Middle East Technical University (METU), Ankara, in 1973. He finished his MSc work at Rensselaer Polytechnic Institute in 1976 and he got his PhD in EEE from the University of Manitoba, Canada, in 1982. He is professor of EEE in METU. His research interests include information systems, software engineering and computer networking. 